\section{Briginal sirticleg.}

\section{WORK OF TIIE MASSACIIUSET'I'S VOLUN'TEER AII) ASS(OCIA'TION IN SAN'TIAGO.}

BY L. a, BHACK HIT, M.D., BOSTON,

In the latter part of July it was decided by the Volunteer Aid Association to send a representative to the island of Cuba who should have direct charge of the distribution of the supplies sent by them, and who could determine from personal observation the needs of the Massachusetts men. Supplies had been sent by different transports, but not being in charge of any one, and there being no one to assume the responsibility for the Association, it was a question whether such supplies would reach their intended destination.

On the 24th of July I was asked to take this position, and start on the 25th with supplies intended for the men in Santingo. 'These supplies consisted of clothing, hospital supplies, prepared food, and delicacies for the sick, besides special contributions by friends and local societies. The lack of information of the conditions in Cuba at this time made the possibilities of the errand uncertain, except that the report of the sufferings from hardships and from disease allowed no doubt of its necessity. My directions from the headquarters of the Association were, therefore, somewhat indefinite, and I was asked to use my judgment in the distribution of supplies taken by me, and those which had already been sent by the Harvard and $Y a l e$, aud after arrival to represent the $\mathbf{A s}_{8-}$ sociation in Santiago. 'The work was intended primarily for the Massachusetts troops, but it was desired that aid should be extended to other volunteers, and to the regulars when such was possible. 'The method of work, therefore, was entirely undecided, and for credentials 1 curried letters from the headquarters of the Massachusetts Volunteer $\Lambda$ id Association, and from Goveruor Wolcott.

It was necessary on account of the blockade and the quarantine of the Suntiago Province to go by the way of Jamaica. Accordingly, arrangements wore made by the Boston Fruit Company to ship the supplies on the steamer Albert Dumois to Jamaica, and to proceed from thence by sailing vessel across to Santiago. 13y courtesy of the Fruit Company, I was enabled to precede the goods and take passage on the steamer Brookline, arriving two days ahead of the Dumois. 'lhen the goods were transferred to a thirty. ton sailing vessel called the Little Wanderer, the spare space in the hold being filled with barrels of limes which were obtained in Port Ontario, and after a three days' trip we reached Santiago.

At the time of arrival the city was in much the same condition as after the surrender, except the work of cleaning the streets had begun, and the American troops were beginning to be sent back to the States. The city was under military law, and was filled with the American and Spanish soldiers, and with the natives, who had not left the province during the siego. 'The city was still in a condition of extreme filth, it was the beginning of the rainy season, and the midsummer heat was intense. There was plenty of the army rations for the well, but a great scarcity of proper food and medicine for the sick and convalescent, und the sickness among our troops, as well as

a Bend bofore the Boston Soclety for Medical Improvemont, Do cember $5,1898$. among the matives and the Spanish prisoners, had begun to be alarming. 'This sickness was principally a pernicious form of malaria, and there was some typhoid, and yellow fever. It was at once apparent that tho special needs which could not be met in the city were suitable food for the sick and convalescent, and hospital supplies, and the Association was at once cabled to that effect. It is to the credit of the oflicials at headquarters that within two days from the receipt of this cablegram a shipment of such supplies was sent.

'The work of the representative of the Association was evident, but the method of carrying this out was met with the greatest difficulty. 'The Cubans were? not disposed to render aid in any way, and could only be persuaded to work by the payment of exorbitant prices, while the lack of interpreters where Spanish alone was spoken made confusion of otherwise simple work. The roads were in such a condition that the transportation by means of the only method possible, the small drays, was extremely slow. I at once reported to Gencral Wood, and he extended evory courtesy to me during the whole of my stay on the island. Every American bad already more than he could do, and therefore one could not look to them for material aid, but every possible assistance to aid in the work was always given to the Association's representative. After a day's search a suitable warehouse was found on Suramados Street near tho water front, and to this the goods were transferred by means of the small drays from the wharf. It was necessary in carrying on this work to constantly guard all of the supplies, otherwise they would be stolen by the native Cubans.

'The work for the Association on the island was evident, for there was no question as to the needs of the men among the troops, and this consisted mainly of food for men in the camp, and hospital clothing and supplies for those in the liospitals. 'The hospitals especially needed prepared fool, soups, stimulants aud hospital clothing, and fortunately there was a generous supply of pajamas, hospital bedding, otc., which was always found to be of great use.

'There were two ways which could be used in the disposition of the supplies, both to the wen in the camp and in the hospitals: One was the personal distribution of the goods, which, under tho circumstances, would havo involved more time than would have been possible to give, particularly sinco no help could be obtained in means of transportation, and it also would have involved the possible friction with the prerogatives of the officials. The other method was to determine the special needs from the surgeons, the commissaries, and such of the oflicials who had charge of supplying the companies, and through them to seo that the goods reached their proper destination. Thero were always some such mon available, through whom such distribution of the goods could be made, and without interference with the regulations and routine, and this proved to be the most satisfactory. The distribution was made according to the comparative relative need, and was sent either by the regimental teams or by stmall drays, which could bo hired in the city. 'This latter always proved to be a slow method, as the loads carried were very small, and usually it was necessary for some one to accompany these supplies to be sure of their safe arrival. At this time nothing in the line of additional food could be obtained in the city; therefore it was necessary to rely 
on the supplies which had been brought, and to make the best disposition possible of them.

At the time of arrival there were two Massachusetts regiments which were camped on the ieland, the $2 d$ and the 9 th. The 2 d were stationed about two miles north of the city, and it was expecterl that they would be sent home within a short time. 'The 9th were camped on the hill at San Juan, and it was generally understood that their stay on the island was probably to be an extended one, which proved to be true. Since the 2d Massachusetts was expected to leave so soon, it had little need of the supplies of clothing, but required food for the sick, both for use in the camp, and on the transport on the way home. At this time some of the supplies, which had been previously sent by the transports Harvard and Yale, arrived in Suntiago, and were taken in churge by the Association. No word was received of their arrival, but one lot was found on the wharf, where it had been unloaded from one of the lighters, and the second lot was found on board one of the large tugboats, to which it had been unloaded from the transport. Many of the boxes had been opened, but in general the shipments arrived in good order. Much of these supplies, as well as selections from the stores in the warehouse, were sent to the camp of this regiment, the selections being mude with the probable short stay of the regiment on the island in view. Fortunately the orders to leave came within a few days, and these supplies were used on board the transport on the way home.

The 9th were in camp three miles from the city, on the San Juan Hill, and had the same general needs as the 2d, but transportation to this regiment was much more difficult, owing to the distance and the condition of the roads. Later in August, from the longer exposure to the hardships of the climate, they being the last to leave the island, their condition became such that the need of additional food for the men on duty and for special food for those sick in quarters was still more urgent. Tho majority of the regiment were using only the hardtack and coffee of the regular rations, and the whole regiment began to show the result of their continued stay on the island. Just before the regiment left for Montauk a shipment of supplies sent by the Association by Mr. Austin arrived, and in time for the use on the way home on the transport. 'This lot of supplies contained a large quautity of prepared food, condensed milk, etc., and proved to be most useful. At the same time soups aud condensed milk could be bought at the commissary department, and a sufficient quantity was obtained to last until reaching Montauk.

During August there was but one hospital, the Nautical Club, in the city under cover, and to this the sickest of the men were sent. It was found that there existed a scarcity at this hospital of hospital clothing, food and stimulants, and of any kind of delicacies for the convalescent. During the month of August frequent donations of these articles, as well as the alkaline waters, which fortunately could be bought in the city, were sent.

About the time when the last detachment of the 9th Regiment had left the island the representative of the Association was asked by General Wood to equip and take charge of a hospital in the city of Santiago. For this there was taken a building formerly built for and used as a hospital by the Cubans, culled the "Centro Benefico," but which had been closed for some months. There was some of the hospital furniture which could be used, but in general it was necessary to select, for supplies could be obtained from different sources throughout the city. Medicines at this time were hard to obtain, but finally were found by collecting from the various sources about the city, and special foods for the patients were collected from the various supplies, which later had begun to come into the city. At this time there was left among the stores a quantity of supplies which could be used as hospital furnishings, and much of this, especially clothing, was used to fill this need of the hospital.

CAMP WIKOFF, MON'IAUK, I. I. ${ }^{1}$

"Y W. H. PRksco'T, M.1., BOs'TON.

I wins to Montauk, August 15th, as agent of the Massachusetts Volunteer Aid $\Lambda$ ssociation, and " to establish a diet kitchen to provide delicacies for the Massachusetts regiments which were coming." I arrived at Camp Wikoff about a week after the first patient was admitted to the hospital, and stayed until there were only twenty patients left.

When I arrived 1 found a great deal of confusion there were few physicians, fewer nurses, and fewer still hospital-corps men, and new tents or wards were being erected.

Among the other causes of confusion were: (1) the limited number of cots; (2) tho difficulty in obtaining supplies (of all sorts); (3) the lack of an index of the patients; (4) the constant changes taking place among the patients; (5) the presence, in the wards, of "outsiders"; (6) the lack of any policing, and, finally, the absence of a firm, controlling hand always within reach. The surgeon in charge, Col. W. 11. Forwood, to whom I applied for permission to erect a diet kitchen (without expense or trouble to the Government), did not consider one necessary, and it was nearly two weeks later when permission was given to Mrs. Valentino Mott, representing the Red Crose Society. Immediately after permission was obtained Mrs. Mary I Iatch Willard, an expert dietitiau sent by tho Red C'rose Auxiliary No. 3, and I, working in learty co-operation, planned, erected and equipped a large diet kitchen with a floor space of over 2,000 square feet, and capable of providing the delicacies needed for 1,500 men. It was intended to show that food could be neatly and satisfactorily prepared in a kitchen in a field hospital, and it fullilled its mission. In addition to the diet kitchen erected at the General Iospital there were eimilar kitcheus (although smaller) provided for the three division hospitals, and additional equipments furnished to the one established at the Detention Ilospital by Dr. L. A. C. Iughes and Miss Fenuessey.

Almost the entire expense of the erection and equipment of these kitchens was borne by the Massachusotts Volunteer Aid Association, as well as the running expenses, until they were turned over to the Government, which had also borne part of the expense of their establishment. $\Lambda$ nd it seems to me that it was only necessary for the outside "helping" societies to cake the initiative, get a thing started, and then turn it over to the Government. In my experience, those in 1 Read boforo the Boston Socioty for Medisal Improvement, Decomber 5, 1898. 